\title{
Fever is not a symptom in COVID -19. None of the diseases require fever as its symptom.
}

K. M. Yacob

Chief Physician, Marma Health Centre, Kerala, India

Corresponding Author: K. M. Yacob, Chief Physician, Marma Health Centre, kalyani Towers, Deshabhimani Jn, P.O. Kaloor, Ernakulam (Dt), Kerala, India, Mob:91 9847094788.

Received date: May 06, 2020: Accepted date: July 25, 2020: Published date: July 31, 2020

Citation: K. M. Yacob (2020) Fever is not a symptom in COVID -19. None of the diseases require fever as its symptom. J General medicine and Clinical Practice. 3(1) DOI: 10.31579/2639-4162/022

Copyright: (02020 K. M. Yacob. This is an open-access article distributed under the terms of the Creative Commons Attribution License, which permits unrestricted use, distribution, and reproduction in any medium, provided the original author and source are credited.

\section{Abstract \\ A practicing physician in the field of healthcare in the state of Kerala in India for the last 31 years and very much interested in basic research. My interest is spread across the fever, inflammation and back pain. I am a writer. I already printed and published nine books on these subjects. I wrote hundreds of articles in various magazines. \\ I also prepared 8000 Affirmative cross checking questions. It can explain all queries related to fever \\ After scientific studies for a long time, I have developed a theory, which can explain all queries related to fever. The real science of fever can be termed as the Physics of fever. \\ I have written 3 books about fever in Malayalam language. \\ Keywords: Symptom Definition, Signals Definition, Symptoms of fever, symptoms of rising temperature}

\section{Introduction:}

We have been hearing for centuries that 'fever is not a disease but a symptom'. Physicians say that fever is a symptom of diseases like flu to cancer.

The conservative fever definition, diagnosis, and treatments are based on fever as a symptom.

All the studies related to fever as a symptom of a disease have been done without knowing the Purpose of the temperature of fever is.

In the current COVID -19 epidemic situation, it has great importance. Because Fever is considered as an important part of Corona disease. Not knowing the purpose of temperature of fever, how can fever included as a symptom in COVID -19?

What is the symptom in COVID -19 according to symptom definition?

In COVID -19 up to $80 \%$ of patients have no fever. Why up to $80 \%$ of patients with the COVID -19 virus have no fever? Is it because there is no need for the care of fever or is it because the disease is free of symptoms?

Without knowing the Purpose of the temperature of fever, how can fever included in the symptom definition?

Any evidence to establish that fever is a symptom in COVID -19?

Is temperature between $38^{\circ}$ to $41^{\circ}$ centigrade can be symptom of a disease?

Most of the diseases may not have fever. Sometimes it disappears. Then, is fever a symptom of which disease?
Is fever a symptom?

what are the scientific criteria or parameters necessary for a Symptom?

What we will do to prove a symptom?

Symptom Definition?

What is the use of Symptom Definition?

As with any or all other definitions, symptom definition should describe the symptom scientifically. If it cannot describe clearly, there is no use of a symptom definition.

\section{Symptom Definition is the only parameter necessary for a Symptom.}

"A symptom is a departure from normal function or feeling which is noticed only by a patient, indicating the presence of disease or abnormality".

A symptom is subjective, observed by the patient and cannot be measured directly, whereas a sign is objectively observable. A symptom can more simply be defined as any feature which is noticed by the patient.

A sign is noticed by other people.

Different types of fever definitions can be seen in medical books. Although the general sense that a fever means an increase in body temperature is pervasive, the exact definition of a fever is an ongoing debate, as is its biological purpose [2].

Davidsons Principles and practice of medicine_22Ed says

Fever' implies an elevated core body temperature of more than $38.0^{\circ} \mathrm{C}$ 
Harrison's Principles of Internal Medicine, 19th Ed says

"Fever is an elevation of body temperature that exceeds the normal daily variation and occurs in conjunction with an increase in the hypothalamic set point".

Not even a single trace of symptom definition can be seen in fever definition and vice versa.

Then according to which scientific basis does fever definition gets related to symptom definition?

\section{In symptom definition, fever definition can't be found.}

The elevation of body temperature is not included in symptom definition.

The main evidence which proves that fever is not a symptom of the disease is symptom definition itself.

\section{A symptom has no ability to make other actions.}

During fever sponging with water is used to reduce temperature, then shivering takes place to produce heat. Shivering is a heat-producing action.

In physical appearance shivering is a warning signal of temperature decreasing; its action is a protective self-defense mechanism of the body. The shivering due to fever never comes under the definition of 'symptom'

\section{An action can never become a symptom.}

Elevation of body temperature is an action like lifting, sitting, or standing. on what scientific basis "elevation" becomes a symptom?

The feeling of elevation in body temperature is a Symptom of fever. If the increment in body temperature is an aftereffect of Elevation of body temperature, according to symptom definition the feeling of increment in body temperature is the symptom of increased temperature.

Is elevated temperature a scientific criteria or parameter of symptom?

No.

The patient cannot feel the elevated body temperature. According to Symptom definition fever is not a symptom. Then what are the criteria to asses a Symptom?

Nobody knows.

Then on which scientific basis can fever be considered as a symptom?

Nobody knows.

This is evidence to establish that fever is not a symptom.

If elevation of body temperature (Fever) is not a symptom, then what?

One cannot be understood directly the temperature is elevated in the hypothalamus. A mechanical device is necessary to measure elevated temperature in the hypothalamus. According to sign definition, it is a sign. Then arise another question about body temperature.

If elevation of body temperature (Fever) is a sign, then in which category will the temperature of fever come under?

Signal category-Everybody can feel. No device is required.

In the beginning stage of fever, the patient and others cannot feel the rising temperature. Elevated temperature or increased temperature never makes fever or symptoms of fever. It may create hyperthermia.

Fever includes so many symptoms like fatigue to mind and body, reduced appetite, reduced motion and indigestion, internal and external discomfort, etc., signals and actions like high temperature, shivering, etc may occur.

\section{Different cause of diseases never shows the same symptoms.}

Different causes of diseases like virus, bacteria, fungi, venom, horror scene, horror dream,... never shows the same symptoms. Its actions are different and sometimes opposite. No similarities can be seen between their actions.

All the symptoms and signals of hypothermia can be seen in fever too. That means there is a common basic science behind these phenomena. In hypothermia, core temperature drops below $35^{\circ} \mathrm{C}(95 \mathrm{~F})$. Hypothermia is a temperature decreasing disease or state. Modern medical science describes fever (pyrexia) as a symptom of diseases in which temperature is increased. Actually increasing temperature and the decreasing temperature is not a symptom, but a signal of a disease. If hypothermia is a temperature decreasing disease or state of threat to life or organs, then temperature increasing fever condition would also be a state of threat to life or organs.

None of the diseases or causes of diseases require fever as its symptom.

If the mosquito bites its virus, bacteria, and venom gets deposited in the body as a result according to nature and strength of Viruses, bacteria, venom symptoms like itching, pain, and signals like colour change, inflammation, etc may occur.we can see the symptoms, Signals, and indications of the virus, bacteria, and venom which multiple or spreading or damages (disease) the body before fever emerge.

Here fever emerges after days, weeks or months after the various stages of spreading the disease. Here fever is not required as its symptom. The disease like Kala Azar, fever emerges after 6 to 8 months from when the germs were deposited in the body. Here without fever, symptoms, Signals, and indications of the disease can be seen up to 8 months.

- If one frightened by a horror scene, horror dream or due to fear of attack, as a result, according to nature and strength of fear symptoms like dread, fear, and signals like shivering, unconsciousness, delirious, etc ..... May occur. Here fever is not required as its symptom. The nature and strength of fear cannot be diagnosed with fever. At the same time, the nature and strength of fear can be diagnosed by its symptoms and signals.

The symptoms of viruses, bacteria, and venom are not based on fever.

The symptom, signs, and signals are shown whenever viruses, bacteria, and venom are present in the body. In such a situation fever is not necessary, because fever is not seen in everyone.

In a state of multi-disease conditions, if fever is caught and cured, the fever will not show the symptoms of other diseases. In H1N1 infections $30 \%$ of patients had no fever.

\section{Patients who have flu to cancer may not have a fever.}

A cancer patient after getting frightened develops fever. If a patient has five to six diseases and fever is caught, the symptoms of fever do not show the symptoms of any other diseases caused. In such a situation, when fever is cured our body shows symptoms of other diseases without symptoms of fever. The nature and strength of viruses, bacteria, and the venom cannot be diagnosed with fever. At the same time, the nature and strength of viruses, bacteria, the venom can diagnose by its symptoms and signals.

The symptoms, signs, signals of fever are only seen at the presence of fever.

The symptoms, signs, signals of fever are only seen at the presence of fever. During cancer, the symptom, signs, and signals of cancer are shown every time. A patient having cancer and fever at the same time, symptoms, 
signs, and signals of both cancer and fever are shown every time. A symptom of cancer never becomes a symptom of fever or a symptom of fever can never become a symptom of cancer.

If fever is a symptom, one symptom has no ability to make other symptoms.

Fever makes numerous symptoms, signals, and actions, etc.

\section{If fever is a symptom we cannot call a person as a fever patient}

If fever is a symptom no treatment is required to reduce fever. Treatment is required only for disease and its cause.

Our immune system never increase elevated the symptom in the hypothalamus.

\section{A symptom can never cause fatal.}

It is said that the temperature above $41^{\circ} \mathrm{C}$ can cause febrile fits ant it may cause fatal. (Actually 'febrile fits' is due to decrease of blood circulation to the brain)

There is a sharp difference between Symptoms of fever and symptoms of rising temperatures.

Symptoms of fever include body pain, fatigue to mind and body, reduced appetite, reduced motion and indigestion, an aversion towards the cold substances, internal and external discomfort, etc.,
Symptoms of rising in temperature include likeness towards cold items, like to drink cold water, feel discomfort while using a blanket, feeling hot, etc. According to the facts of physics, if temperature increases, thermal expansion of an object is positive it will expand and with a decrease of temperature, it will shrink.

On the contrary, during fever we can see blood vessels and skin are shrunk, pressure decreases, body shivers, sleep increases, motion decreases, inflammation increases, body pain increases, blood circulation decreases, dislike cold substances, etc...

In fever, the firing rate of Warm sensitive neurons decreases, and the firing rate of Cold sensitive neurons increases.

At the same time if we apply hotness from outside by thermal bag or if we drink hot water, our body acts according to the Facts of Physics- an increase of temperature, the pressure will also increase, expands blood vessels and skin, body sweats, motion will increase, inflammation will decrease, body pain will decrease, blood circulation will increase, like cold substances, etc..

There are no similarities between the Symptoms of fever and symptoms of rising temperatures. Fever never shows symptoms of rising temperature like decreased body pain, like cold substances, hate hot substances, feel discomfort while using a blanket, etc...

We can prepare a table showing symptoms, signs, signals, and actions of disease, fever and rising temperature.

\begin{tabular}{|c|c|c|c|c|}
\hline \multicolumn{5}{|c|}{$\begin{array}{l}\text { Yacob's Table Showing symptoms, signs, signals, and actions of disease, } \\
\text { fever, and rising temperature. }\end{array}$} \\
\hline \multicolumn{2}{|l|}{ Symptoms of fever } & \multicolumn{2}{|c|}{ Symptoms of rising temperature } & $\begin{array}{l}\text { Symptoms of } \\
\text { disease }\end{array}$ \\
\hline \multicolumn{2}{|c|}{\begin{tabular}{|} 
Bitter taste, body pain, fatigue to mind and \\
body, reduced appetite, reduced motion and \\
indigestion, an aversion towards the cold sub- \\
stances, internal and external discomfort, etc \\
\end{tabular}} & \multicolumn{2}{|c|}{\begin{tabular}{|l|l|} 
Like cold substances, like to \\
drink cold water, feel discomfort \\
while using a blanket, feeling hot, \\
decrease body pain, etc.
\end{tabular}} & $\begin{array}{l}\text { According to } \\
\text { disease }\end{array}$ \\
\hline Signals of fever & \multicolumn{3}{|c|}{ Signals of rising temperature } & $\begin{array}{l}\text { Signals of } \\
\text { disease }\end{array}$ \\
\hline \begin{tabular}{|l|l} 
Shrink blood vessels and skin, & $\mathrm{H}$ \\
shivering, temperature rise in be- & a \\
tween $38^{\circ}$ to $41^{\circ}$ centigrade. & $\mathrm{i}$ \\
\end{tabular} & \multicolumn{3}{|c|}{$\begin{array}{l}\text { Expands blood vessels and skin, body sweats, } \\
\text { an increase of temperature, the pressure will also } \\
\text { increase, uncontrolled high temperature, ...etc }\end{array}$} & $\begin{array}{l}\text { According to } \\
\text { disease }\end{array}$ \\
\hline Signs and actions of fever & \multicolumn{2}{|c|}{$\begin{array}{l}\text { Signs and actions of } \\
\text { rising temperature }\end{array}$} & \multicolumn{2}{|c|}{$\begin{array}{l}\text { Signs and actions } \\
\text { of disease }\end{array}$} \\
\hline $\begin{array}{l}\text { The firing rate of Warm sensitive } \\
\text { neurons decreases, and the firing rate } \\
\text { of Cold sensitive neurons increases, } \\
\text { increase of prostaglains, .....etc }\end{array}$ & \multicolumn{2}{|c|}{$\begin{array}{l}\text { The firing rate of Warm } \\
\text { sensitive neurons increases and } \\
\text { the firing rate of Cold sensitive } \\
\text { neurons decreases, }\end{array}$} & \multicolumn{2}{|c|}{$\begin{array}{l}\text { Numerous signs like } \\
\text { pressure decreases or } \\
\text { increases, Blood } \\
\text { circulation decreases,.. }\end{array}$} \\
\hline
\end{tabular}

How can we separate symptoms of the disease and symptoms of fever and symptoms of rising temperatures?

A fever condition means symptoms, signs, signals, and actions of both disease and fever are included.

If we deduct disease from fever condition, we will get the fever. So we can make an equation:-
1. Fever condition (Disease + Fever $)-$ Disease $=$ Fever

Symptoms in fever condition, both symptoms of disease and symptoms of fever are included. If we deduct symptom of disease from total symptoms of fever condition, we will get symptoms of fever.

2. Symptoms in fever condition (Symptoms of disease +Symptoms of Fever) - Symptoms of disease $=$ Symptoms of Fever. 
Like that we can separate signs, signals, and actions of both fever and disease.

Signals in fever condition, both signals of disease and signals of fever are included.

3. Signals in fever condition (Signals of disease +Signals of Fever) Signals of disease $=$ Signals of Fever

Signs in fever condition, both signs of disease and signs of Fever are included.

4. Signs in fever condition (Signs of disease + Signs of Fever) - Signs of disease $=$ Signs of Fever

Actions in fever condition, both actions of disease and actions of Fever are included.

5. Actions in fever condition (Actions of disease +Actions of Fever) Actions of disease $=$ Actions of Fever.

In fever does not show any actions of temperature rise.A new fever definition, diagnosis and treatment is required.

If a person who believes in conservative fever definition, diagnosis and treatment he cannot recognize these equations

\begin{tabular}{|l|l|}
\hline \multicolumn{2}{|c|}{$\begin{array}{l}\text { Yacob's Equations of separating fever, hyperthermia, symptoms, Signals, } \\
\text { Signs and actions from Fever conditions and Hyperthermia conditions? }\end{array}$} \\
\hline Fever condition & \multicolumn{1}{|c|}{ Hyperthermia condition } \\
\hline $\begin{array}{l}\text { 1. Fever condition(Disease +Fever) - Dis- } \\
\text { ease =Fever. }\end{array}$ & $\begin{array}{l}\text { 1. Hyperthermia condition (Disease + Hyperthermia) } \\
\text { - Disease = Hyperthermia. }\end{array}$ \\
\hline $\begin{array}{l}\text { 2. Symptoms in fever condition (Symptoms } \\
\text { of disease +Symptoms of Fever) - } \\
\text { Symptoms of disease= Symptoms of Fever. }\end{array}$ & $\begin{array}{l}\text { 2. Symptoms in hyperthermia condition (Symptoms } \\
\text { of disease +Symptoms of Hyperthermia) - Symptoms } \\
\text { of disease = Symptoms of Hyperthermia. }\end{array}$ \\
\hline $\begin{array}{l}\text { 3. Signals in fever condition } \\
\text { (Signals of disease +Signals of Fever) } \\
\text { - Signals of disease= Signals of Fever. }\end{array}$ & $\begin{array}{l}\text { 3. Signals in Hyperthermia condition (Signals of } \\
\text { disease +Signals of hyperthermia) - Signals of disease } \\
\text { = Signals of Hyperthermia. }\end{array}$ \\
\hline $\begin{array}{l}\text { 4. Signs in fever condition (Signs of } \\
\text { disease +Signs of Fever) - Signs of disease } \\
=\text { Signs of Fever. }\end{array}$ & $\begin{array}{l}\text { 4. Signs in Hyperthermia condition (Signs } \\
\text { disease + Signs of Hyperthermia) - Signs of disease } \\
\text { = Signs of Hyperthermia }\end{array}$ \\
\hline $\begin{array}{l}\text { 5. Actions in fever condition (Actions of } \\
\text { disease +Actions of Fever) - Actions of } \\
\text { disease = Actions of Fever }\end{array}$ & $\begin{array}{l}\text { 5. Actions in Hyperthermia condition (Actions of } \\
\text { disease +Actions of Hyperthermia) - Actions of } \\
\text { disease = Actions of Hyperthermia. }\end{array}$ \\
\hline
\end{tabular}

\section{How can we prove the fever is not a symptom?}

The fever is not symptom when examined in various directions.

We can separate symptoms of fever and symptoms of disease and symptoms of rising temperatures. Like that we can separate signs, signals, and actions of fever and disease and rising temperature.

If we ask any type of question-related to fever by assuming that the fever is not a symptom we will get a clear answer. If we avoid or evade from this we will never get a proper answer to even a single question.

If we do any type of treatment by assuming that the fever is not a symptom, the body will accept, at the same time body will resist whatever treatment to decrease blood circulation. Besides that, we used the symptom definition. No further evidence is required to prove the fever is not a symptom.

\section{The benefit of terming the Fever temperature as a signal:}

The purpose of the definition for signal is to analyze the signal scientifically, to differentiate it and also to brief it and understand it easily.

If we say there exists temperature as a signal, one can easily understand without much explanation. In such a situation, automatically comes apt word as well as apt definition.

That is why it is told to exclude the temperature of fever from symptoms of the disease.

\section{Conclusion.}

The fever is not symptom when examined in various directions.
Temperature between 38 degrees and 41 degrees cannot be a symptom of any of the diseases.

A different cause of diseases like virus, bacteria, fungi, venom, horror scene, and horror dream never shows the same symptoms.

Opposite diseases never show the same symptoms.

When the disease becomes a threat to life or organs, the temperature of fever is a warning signal of a disease.

Fever has never been scientifically proved as a symptom of a disease. Fever has the properties of adaptation.

Fever treatment should be revised according to the warning signal of a disease. A new fever definition, diagnosis and treatment is required.

It is wonderful that a physician having years of experience in fever treatment cannot understand actual fever definition and fever treatment have no relation with symptom definition and diagnosis.

In the early days of my discovery, I thought that fever is a symptom of disease. I never got any answers for even a single question about symptoms. That induced me to find out the real truth of fever. I can eliminate fever definition, diagnosis and treatment. If you discard this discovery it would be an injustice to mankind.

\section{References}

1. Harrison's Principles of Internal Medicine, 19th Ed

2. Davidsons Principles and practice of medicine_22Ed.

3. Guyton and Hall,Text book of Medical Physiology- $11^{\text {th }}$ Ed 
4. Nelson Text book of Pediatrics $20^{\text {th }} \mathrm{Ed}$

5. R.S.Satoskar, S.D.Bhandarkar, Nirmala N.RegePharmacology and pharmacotherapeutics -Revised XIV edition, p.159, 160, 163, 170).

6. Berman's Pediatric Decision Making (5th edition) 2011.

7. Allen R myres,MD National Medical Series For Independent Study-nms Medicine $4^{\text {th }}$ edition

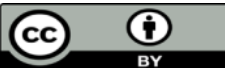

This work is licensed under Creative Commons Attribution 4.0 License

To Submit Your Article Click Here: Submit Article
Ready to submit your research? Choose Auctores and benefit from:

* fast, convenient online submission

* rigorous peer review by experienced research in your field

* rapid publication on acceptance

* authors retain copyrights

* unique DOI for all articles

* immediate, unrestricted online access

At Auctores, research is always in progress.

Learn more www.auctoresonline.org/journals/general-medicine-andclinical-practice- 